\title{
Zinc Phthalocyanine-Graphene Hybrid Material for Energy Conversion: Synthesis, Characterization, Photophysics and Photoelectrochemical Cell Preparation
}

\author{
Nikolaos Karousis ${ }^{\S}$, Javier Ortiz ${ }^{\dagger}$, Kei Ohkubo ${ }^{*}$, Taku Hasobe ${ }^{\ddagger^{*}}$, Shunichi Fukuzumi ${ }^{\ddagger}, \#^{*}$, Ángela \\ Sastre-Santos $^{\dagger^{*}}$, and Nikos Tagmatarchis ${ }^{{ }^{*}}$

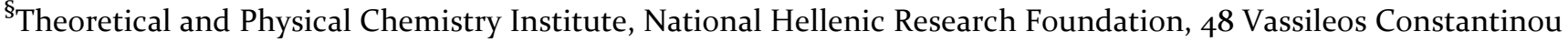 \\ Avenue, Athens 116 35, Hellas \\ ${ }^{\dagger}$ Division de Química Orgánica, Instituto de Bioingeniería, Universidad Miguel Hernández, Elche 03202, Spain \\ ${ }^{\ddagger}$ Department of Chemistry, Faculty of Science and Technology, Keio University, Yokohama, 223-8522, Japan \\ ${ }^{*}$ Department of Material and Life Science, Graduate School of Engineering, Osaka University, ALCA, Japan Science \\ and Technology Agency (JST), Suita, Osaka, 565-0871, Japan \\ \#Department of Bioinspired Science, Ewha Womans University, Seoul 120-750, Korea \\ Supporting Information Placeholder \\ Keywords: graphene; functionalization; phthalocyanine; hybrids; characterization; photophysics.
}

\begin{abstract}
Graphene exfoliation upon tip sonication in o-DCB was accomplished. Then, covalent grafting of (2aminoethoxy)(tri-tert-butyl) zinc phthalocyanine (ZnPc), to exfoliated graphene sheets was achieved. The newly formed ZnPc-graphene hybrid material was found soluble in common organic solvents without any precipitation for several weeks. Application of diverse spectroscopic techniques verified the successful formation of ZnPc-graphene hybrid material, while thermogravimetric analysis revealed the amount of ZnPcloading onto graphene. Microscopy analysis based on AFM and TEM was applied to probe the morphological characteristics and to investigate the exfoliation of graphene sheets. Efficient fluorescence quenching of ZnPc in the ZnPc-graphene hybrid material suggested that photoinduced events occur from the photoexcited ZnPc to exfoliated graphene. The dynamics of the photoinduced electron transfer was evaluated by femtosecond transient absorption spectroscopy, thus, revealing the formation of transient species such as $\mathrm{ZnPc}^{\circ+}$ yielding the charge-separated state $\mathrm{ZnPc}^{{ }^{+}-\text {graphene }}{ }^{-}$. Finally, the $\mathrm{ZnPc}$-graphene hybrid material was integrated into a photoactive electrode of an optical transparent electrode (OTE) cast with nanostructured $\mathrm{SnO}_{2}$ films $\left(\mathrm{OTE} / \mathrm{SnO}_{2}\right)$, which exhibited stable and reproducible photocurrent responses and the incident photon-to-current conversion efficiency was determined.
\end{abstract}

\section{INTRODUCTION}

Graphene is an outstanding material, consisting of a two-dimensional $(2 \mathrm{D})$ single layer of $\mathrm{sp}^{2}$-hybridized carbon atoms bonded together in a hexagonal "honeycomb" lattice and presents remarkable mechanical and thermal properties. ${ }^{1,2}$ Moreover, electrons can travel up to micrometers on graphene plane without being scattered off by defects sites, giving to graphene a remarkably high electrical conductivity. ${ }^{3-7}$ These exceptional properties of graphene make it an ideal candidate in construction of transparent conducting electrodes that could be used in energy conversion and storage systems. ${ }^{8,9}$ Additionally, both sides of graphene's double-sided plane are free to participate in a great plethora of organic reactions offering an alternative approach to the control of its electronic properties. $^{10,11}$

Fabrication of graphene onto substrates requires exfoliation in the form of single or even few layers as well as fine dispersion in common organic solvents, while at the same time the honeycomb lattice retains its integrity without breaking in small particles. In this context, the contribution of chemical exfoliation under mild conditions and the organic covalent functionalization is of great importance. In the field of exfoliation of graphite, a common strategy followed is through the use of molecules that are able to penetrate the graphite structure and overcome the strong Van der Waals interactions, supporting the multiple graphene layers in graphite, thus leading to stable suspensions. ${ }^{12-16}$ Recently, a variety of strategies became also available introducing organic addends covalently attached onto the surface of exfoliated graphene, thus yielding soluble graphene-based materials. ${ }^{17}$ Moreover, some novel graphene-based hybrid materials, in which the unique properties of graphene are combined with those of $\mathrm{Eu}^{18} \mathrm{Au}^{19}$ or $\mathrm{CdS}^{20}$ nanoparticles as well as photoactive components such as porphyrins, ${ }^{21-26}$ pyrenes $^{27^{2-}}$ ${ }^{29}$ and recently electroactive exTTF, ${ }^{30,}{ }^{31}$ have been pre- 
pared and shown that photoillumination induces intrahybrid charge-separation. However, none of those materials have been tested so far in energy conversion schemes as active components (i.e. photoanodes) in prototype devices. Actually, the only example in which a graphene-based hybrid material integrated as component in a photovoltaic cell concerns a supramolecularly interacting zinc phthalocyanine-poly( $p$-phenylene vinylene) with graphene. $^{32}$ Therefore, it is absolutely timely to prepare new graphene-based materials and exploit them on the search for advancing the incident photo-to-current conversion efficiency (IPCE).

Phthalocyanines are aromatic macrocycles with a high electronic delocalization and an intense absorption in the red-near IR zone. They possess a great thermal and photochemical stability and are very versatile, since it is possible to change the central atom and to introduce substituents in the peripheral and axial positions, thus bringing the possibility to tune their physicochemical and optical properties. $^{33,34}$ In addition to their applications as photosensitizers for photodynamic therapy, ${ }^{35,36}$ as liquid crystals, ${ }^{37,38}$ and in nonlinear optics, ${ }^{39,40}$ phthalocyanines have emerged with force in the field of photovoltaic devices. They have been used in bulk heterojunction organic solar cells ${ }^{41-43}$ and particularly, in dye-sensitized solar cells (DSSCs), ${ }^{44-46}$ as lower-cost and efficient red-absorbing substitutes for standard ruthenium polypyridyl dyes. Recently, there have been substantial increases in power conversion efficiencies in DSSCs using unsymmetrically substituted "push-pull" zinc phthalocyanines with bulky substituents. ${ }^{47-50}$ Among them, phthalocyanines have been also covalently and non-covalently connected with different electron acceptor carbon nanostructures, ${ }^{51,52}$ such as $\mathrm{C}_{60},{ }^{53-56} \mathrm{C}_{59} \mathrm{~N},{ }^{57}$ carbon nanotubes, ${ }^{58}$ perylenebisimides ${ }^{59^{-66}}$ and the photoinduced electron and/or energy transfer properties of these systems have been studied for their use as artificial photosynthetic systems and in organic solar cells.

In the present work, we follow the direct nucleophilic addition $^{67,68}$ of primary amines to carbon nanostructured materials for the covalent functionalization of chemically exfoliated graphene, as derived upon ultrasonication treatment with o-dichlorobenzene (o-DCB), with the custom synthesized (2-aminoethoxy)(tri-tert-butyl) zinc phthalocyanine $(\mathrm{ZnPc}) \mathbf{1}^{60}, 62,69$ (Scheme 1) serving as light-driven electron donor. The aim of the current research is four-fold, namely (i) to succeed in the chemical exfoliation of graphene sheets, (ii) to covalently anchor ZnPc dye to exfoliated graphene, (iii) to assess the photophysical properties of ZnPc-graphene hybrid material, and eventually (iv) to assemble and fabricate the graphene-based hybrid material as photoanode in a prototype photoelectrochemical cell. The new graphene-based nanohybrid material 2, in which $\mathrm{ZnPc}$ is anchored to the graphitic network through a covalent bond, is rendered soluble in common organic solvents and characterized by complementary spectroscopic, thermal and microscopy techniques. Furthermore, photoinduced intrahybrid electron transfer phenomena were investigated and significant photophysical parameters were evaluated. Most importantly, a prototype device was constructed by fabricating the graphene-based hybrid material as photoanode in a photoelectrochemical cell and its efficiency and response were examined. Notably, in the current study both the presence of the short ethylene chain interconnecting $\mathrm{ZnPc}$ with the exfoliated graphene sheet allowing free rotation and flexibility of the photoactive unit as well as the zinc-metallated phthalocyanine itself eventually promoted strong electronic interactions between the two components of the hybrid material to register clearly an efficient photoconversion. 
Scheme 1. Covalent functionalization of exfoliated graphene sheets with ZnPc in o-DCB.
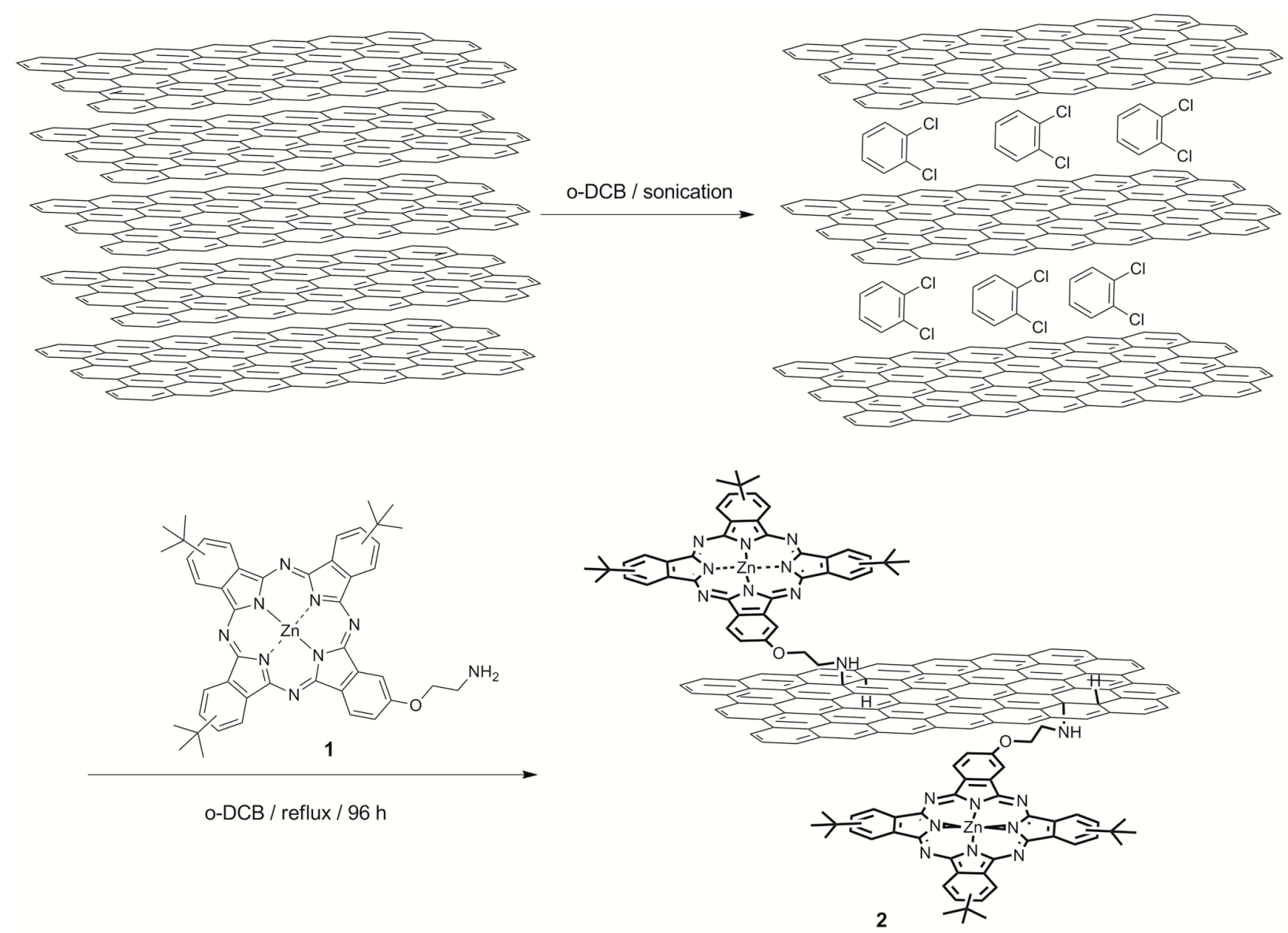


\section{EXPERIMENTAL SECTION}

Steady-State Absorption Spectroscopy. The electronic absorption spectra were recorded on a Perkin Elmer (Lambda 19) UV-Vis-NIR spectrophotometer.

Attenuated-Total-Reflectance Infrared Spectroscopy. Mid-infrared spectra in the region $550-4000 \mathrm{~cm}^{-1}$ were obtained on a Fourier Transform IR spectrometer (Equinox 55 from Bruker Optics) equipped with a single reflection diamond ATR accessory (DuraSampiIR II by SensIR Technologies). A drop of the solution was placed on the diamond surface, followed by evaporation of the solvent, in a stream of nitrogen, before recording the spectrum. Typically, 100 scans were acquired at $4 \mathrm{~cm}^{-1}$ resolution.

Raman Spectroscopy. Micro-Raman scattering measurements were performed at room temperature in the backscattering geometry using a RENISHAW inVia Raman microscope equipped with a CCD camera and a Leica microscope. A 2400 lines $\mathrm{mm}^{-1}$ grating was used for all measurements, providing a spectral resolution of \pm 1 $\mathrm{cm}^{-1}$. As an excitation source the $\mathrm{Ar}^{+}$laser $(514 \mathrm{~nm}$ with less than $0.5 \mathrm{~mW}$ laser power) was used. Measurements were taken with 60 seconds of exposure times at varying numbers of accumulations. The laser spot was focused on the sample surface using a long working distance 5ox objective. Raman spectra were collected on numerous spots on the sample and recorded with Peltier cooled CCD camera. The intensity ratio $\mathrm{I}_{\mathrm{D}} / \mathrm{I}_{\mathrm{G}}$ was obtained by taking the peak intensities following any baseline corrections. The data were collected and analyzed with Renishaw Wire and Origin software.

TEM Analysis. TEM observations were carried out using a JEM-2010F (JEOL) equipped with a CEOS post specimen spherical aberration corrector ( $C$ s corrector) operating at $120 \mathrm{kV}$. The ZnPc-graphene specimen was dispersed in $n$-hexane and then fixed on a copper TEM grid coated with holey carbon film.

Atomic-Force Microscopy. Atomic force microscopy (AFM) measurements were performed in tapping mode with a Quesant Q-Scope 250 atomic force microscope (Quesant Instrument Co., USA) equipped with a $40 \mu \mathrm{m}$ Dual PZT scanner. The images were obtained in ambient conditions with an NSC16 $\left(\mathrm{W}_{2} \mathrm{CSi}_{3} \mathrm{~N}_{4}\right)$ silicon cantilever. Imaging was performed on different scanning areas at a maximum scanning rate of $6 \mathrm{~Hz}$ and with image resolution $600 \times 600$ pixels in broadband mode. The microscope was enclosed in an acoustic/thermal isolation unit. For the measurement, a dispersion of $0.2 \mathrm{mg} / \mathrm{mL}$ in DMF of the sample was sonicated for $30 \mathrm{~min}$ and a few drops were dropcasted on a Si wafer surface. The Si wafer was dried at ambient conditions for $24 \mathrm{~h}$, and directly examined with the AFM instrument.

Photoluminescence Spectroscopy. Steady-state emission spectra were recorded on a Fluorolog-3 Jobin Yvon-Spex spectrofluorometer (model GL3-21).

Fluorescence Lifetime. Picosecond time resolved fluorescence spectra were measured by time correlated sin- gle photon counting (TCSPC) method on a NanoLog spectrofluorometer (Horiba Jobin Yvon), using a laser diode as an excitation source (NanoLED, $376 \mathrm{~nm}, 100 \mathrm{ps}$ pulse width) and by using a streakscope (Hamamatsu Photonics, $\mathrm{C}_{5680}$ ) as a detector and the laser light (Hamamatsu Photonics M10306, laser diode head, $408 \mathrm{~nm}$ ) as an excitation source. Lifetimes were evaluated with the DAS6 Fluorescence-Decay Analysis Software.

Femtosecond Laser Flash Photolysis. Femtosecond transient absorption spectroscopy experiments were conducted using an ultrafast source: Integra-C (Quantronix Corp.), an optical parametric amplifier: TOPAS (Light Conversion Ltd.) and a commercially available optical detection system: Helios provided by Ultrafast Systems LLC. The source for the pump and probe pulses were derived from the fundamental output of Integra-C $(\lambda=786$ $\mathrm{nm}, 2 \mathrm{~mJ} /$ pulse and $\mathrm{fwhm}=130 \mathrm{fs}$ ) at a repetition rate of 1 $\mathrm{kHz} .75 \%$ of the fundamental output of the laser was introduced into a second harmonic generation (SHG) unit: Apollo (Ultrafast Systems) for excitation light generation at $\lambda=393 \mathrm{~nm}$, while the rest of the output was used for white light generation. The laser pulse was focused on a sapphire plate of $3 \mathrm{~mm}$ thickness and then white light continuum covering the visible region from $\lambda=410 \mathrm{~nm}$ to $800 \mathrm{~nm}$ was generated via self-phase modulation. A variable neutral density filter, an optical aperture, and a pair of polarizer were inserted in the path in order to generate stable white light continuum. Prior to generating the probe continuum, the laser pulse was fed to a delay line that provides an experimental time window of $3.2 \mathrm{~ns}$ with a maximum step resolution of $7 \mathrm{fs}$. In our experiments, a wavelength at $\lambda=393 \mathrm{~nm}$ of SHG output was irradiated at the sample cell with a spot size of $1 \mathrm{~mm}$ diameter where it was merged with the white probe pulse in a close angle $(<$ $\left.10^{\circ}\right)$. The probe beam after passing through the $2 \mathrm{~mm}$ sample cell was focused on a fiber optic cable that was connected to a CMOS spectrograph for recording the time-resolved spectra $(\lambda=410-1600 \mathrm{~nm})$. Typically, 1500 excitation pulses were averaged for 3 seconds to obtain the transient spectrum at a set delay time. Kinetic traces at appropriate wavelengths were assembled from the time-resolved spectral data. All measurements were conducted at room temperature.

Photoelectrochemical Measurements. Photoelectrochemical measurements were carried out in a standard two-compartment cell consisting of a working electrode, a Pt wire gauze counter electrode. A KEITHLEY 2400 was used for recording I-V characteristics and photocurrent generation density under an AM 1.5 simulated light source (OTENTO-SUN II, Bunkoh Keiki Co., LTD). For the IPCE measurements, a monochromator (SM-25, Bunkoh Keiki Co., LTD) was introduced into the path of the excitation beam (300 W xenon lamp, Bunkoh Keiki Co., LTD) for the selected wavelength. The lamp intensity at each wavelength was determined using a Si photodiode (Hamamatsu Photonics S1337-1010BQ) and corrected.

EPR Measurements. A quartz EPR tube (internal diameter: $4.5 \mathrm{~mm}$ ) containing a deaerated $\mathrm{PhCN}$ solution of 
ZnPc-graphene 2 was irradiated in the cavity of the EPR spectrometer with the focused light of a 1000-W highpressure Hg lamp (Ushio-USHioo5D) through an aqueous filter at low temperature. EPR spectra in frozen cyclohexane were measured under nonsaturating microwave power conditions using a JEOL X-band spectrometer (JES-RE1XE) with an attached variable temperature apparatus. The magnitude of modulation was chosen to optimize the resolution and the signal-to-noise $(S / N)$ ratio of the observed spectra when the maximum slope linewidth of the EPR signals was unchanged with a larger modulation magnitude. The $g$ value was calibrated with a $\mathrm{Mn}^{2+}$ marker.

Exfoliation of Graphite Flakes. Graphite flakes (200 $\mathrm{mg}$ ) were placed in a cylindrical vial with $100 \mathrm{~mL} o$-DCB. The mixture was sonicated using a Bandelin Sonoplus Ultrasonic Homogenizer HD 3200 equipped with a flat head probe $\left(\mathrm{VS}_{70} \mathrm{~T}\right)$, running at $10 \%$ of maximum power $(25 \mathrm{~W})$ for $15 \mathrm{~min}$ and then using a Soltec Sonica 3300 ETH-S3 sonic bath for another 2.5 hours. The ink-like graphene dispersion was centrifuged using an Eppendorf 5702 at $3500 \mathrm{rpm}$ for $15 \mathrm{~min}$ and the supernatant collected.

Preparation of ZnPc-Graphene Hybrid Material. Exfoliated graphene in 0 -DCB $(0.13 \mathrm{mg} / \mathrm{mL})$ was treated with $\mathrm{ZnPc} 1(6.8 \mathrm{mg}, 8 \mu \mathrm{mol})$ at $120{ }^{\circ} \mathrm{C}$ for 96 hours and then the mixture was filtered through PTFE (o.1 $\mu \mathrm{m}$ pore size) and washed thoroughly with o-DCB, methanol and dichloromethane. The product $(11.2 \mathrm{mg}$ ) collected from the top of the filter was found to form a stable ink-like dispersion in dichloromethane.

\section{RESULTS AND DISCUSSION}

Covalent functionalization of exfoliated graphene sheets is an attractive way of incorporating functional organic moieties with interesting properties directly onto the graphene layer via stable and robust bonds. Especially when a photoactive unit is added, such covalent attachment can result in more efficient electronic communication of the photoactive moiety with the graphene part, as opposed to non-covalent interactions. Initially, based on that, exfoliation of few-layered graphene sheets from graphite flakes, in the presence of $o-\mathrm{DCB}$, was achieved after tip-sonication for a limited time period (i.e. $15 \mathrm{~min}$ ) followed by milder ultrasonication for longer time (i.e. 2.5 h). Then, thermal reaction between exfoliated graphene sheets and $\mathrm{ZnPc} \mathbf{1}$, carrying an alkylamino chain as substituent, resulted in the nucleophilic addition of phthalocyanine moieties onto the graphene's basal plane forming ZnPc-graphene 2 (Scheme 1). Hybrid material 2 found to form black solutions in common organic solvents (i.e. dichloromethane, THF, acetonitrile), stable for several weeks, without observing any precipitation, which allowed proceeding with spectroscopic studies in solution.

The as-prepared exfoliated graphene sheets have average size (i.e. $650 \mathrm{~nm}$ length; $350 \mathrm{~nm}$ diameter) and form ink-like stable dispersions in o-DCB. Morphological evaluation of exfoliated graphene was performed with transmission electron microscopy. Although it is obvious from
TEM images that identification of the exact number of exfoliated graphene sheets cannot be accurately measured, the absence of large graphitic particles guarantees the efficiency of the exfoliation protocol followed. The presence of overlapping oligolayered graphene flakes, with typical folding and ripple patterns, being few to several hundred nanometers size in the periphery, are shown in Figure 1a. Imaging of ZnPc-graphene $\mathbf{2}$ by electron microscopy did not show any alterations on the morphology of the newly formed hybrid material as compared to exfoliated graphene. The particle size distribution of ZnPcgraphene hybrid material was estimated by dynamic light scattering measurements as the average diameter for the hybrid material is around $750 \mathrm{~nm}$ in dichloromethane solution (Figure 1b). Further insight on the nanosized structure of ZnPc-graphene hybrid material derived from AFM. Analyzing several AFM images, graphene sheets reaching almost $0.5 \mu \mathrm{m}$ in the lateral dimension, with height of around $3 \mathrm{~nm}$ were found. Considering the height of a single graphene sheet to be less than $1 \mathrm{~nm}$ and the added contribution from the attached ZnPc moiety, it is reasonable to expect that the obtained images are representative of single- and/or bi-layers of ZnPc-graphene sheets (Figure 1c). Obviously, oligo-layered graphene sheets were also present.

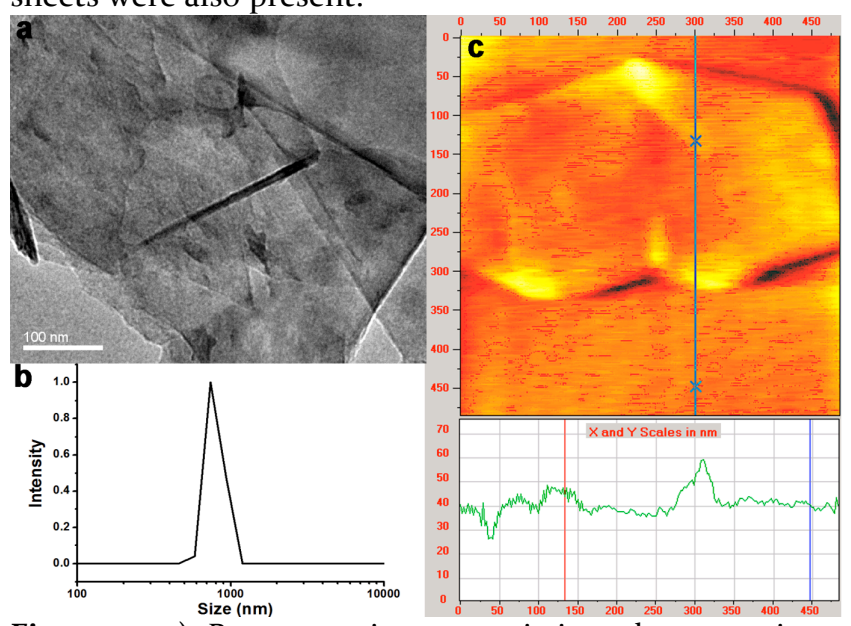

Figure 1. a) Representative transmission electron micrograph of exfoliated graphene. b) DLS distribution of ZnPcgraphene hybrid material, obtained in dichloromethane. c) AFM image of ZnPc-graphene and profile analysis showing a height of $3 \mathrm{~nm}$.

Raman spectroscopy is a powerful tool for characterizing materials possessing conjugated carbon $\mathrm{sp}^{2}$ hybridized bonds, such as graphene, due to their intense Raman signals. A detailed micro-Raman spectroscopy characterization was carried out for ZnPc-graphene material 2 and the corresponding spectrum is shown in Figure 2. The Raman spectrum of exfoliated graphene shows a D-band at $1353 \mathrm{~cm}^{-1}$ due to exfoliation, a sharp G-band at $1582 \mathrm{~cm}^{-1}$ red-shifted by ca. $1 \mathrm{~cm}^{-1}$ as compared with pristine graphite and a $2 \mathrm{D}$-band at $2725 \mathrm{~cm}^{-1}$ lowered and broadened as compared with intact graphite, proving the existence of exfoliated sheets in the examined sample. The ZnPcgraphene hybrid material 2 shows a similar Raman spectrum with exfoliated graphene, with an enhanced D band $\left(I_{\mathrm{D}} / I_{\mathrm{G}}=0.35\right.$ for 2 vs 0.19 for exfoliated graphene) due to 
$\mathrm{sp}^{3}$ carbons generated on the graphitic lattice upon the covalent attachment of $\mathrm{ZnPc}$.

Intact graphite does not show any significant vibrations in the IR spectrum. In contract, in the attenuatedtotal-reflectance-IR spectrum of ZnPc-graphene hybrid material 2 (Figure $\mathrm{S}_{1}$ in the $\mathrm{SI}$ ), the $\mathrm{C}-\mathrm{H}$ stretching vibrations due to the ZnPc unit were identified at 2850-2950 $\mathrm{cm}^{-1}$, while the characteristic fingerprint of $\mathrm{ZnPc}$ bands

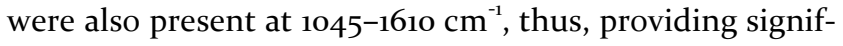
icant support for ZnPc covalently bonded onto exfoliated graphene.

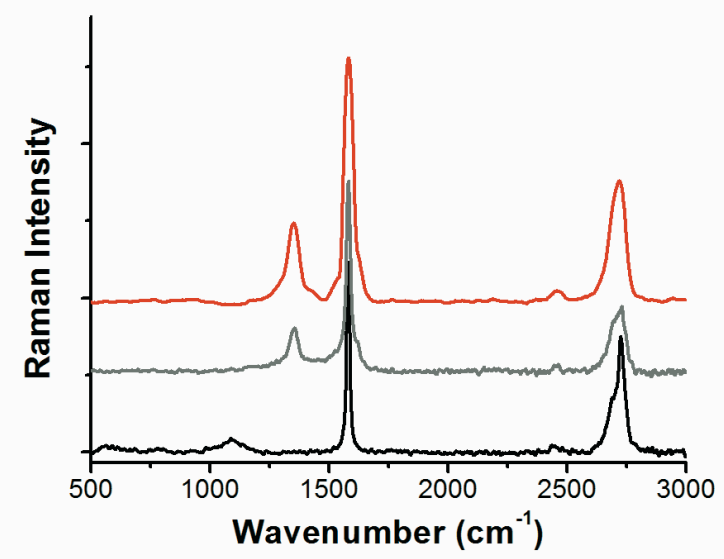

Figure 2. Raman spectra of pristine graphite (black), exfoliated graphene (grey) and ZnPc-graphene hybrid material 2 (red), obtained at $\lambda_{\text {exc }}=514 \mathrm{~nm}$.

The amount of $\mathrm{ZnPc}$ covalently anchored onto the graphene lattice was evaluated by thermogravimetric analysis. Pristine graphite is thermally stable under nitrogen atmosphere up to at least $800{ }^{\circ} \mathrm{C}$. On the other hand, the TGA graph of ZnPc-graphene 2 revealed a $12 \%$ weight loss, in the temperature range of $200-500{ }^{\circ} \mathrm{C}$ (Figure 3 ), which is attributed to the thermal decomposition of $\mathrm{ZnPc}$ covalently attached to graphene sheets. Taking into account that value, the number of graphene carbon atoms per $\mathrm{ZnPc}$ unit is estimated, thus giving a functionalization degree of one $\mathrm{ZnPc}$ per every 518 carbon atoms, in $\mathrm{ZnPc}-$ graphene hybrid material 2. The weight loss occurred above $500{ }^{\circ} \mathrm{C}$, is attributed to the thermal decomposition of defects created at sites where graphene functionalization took place.

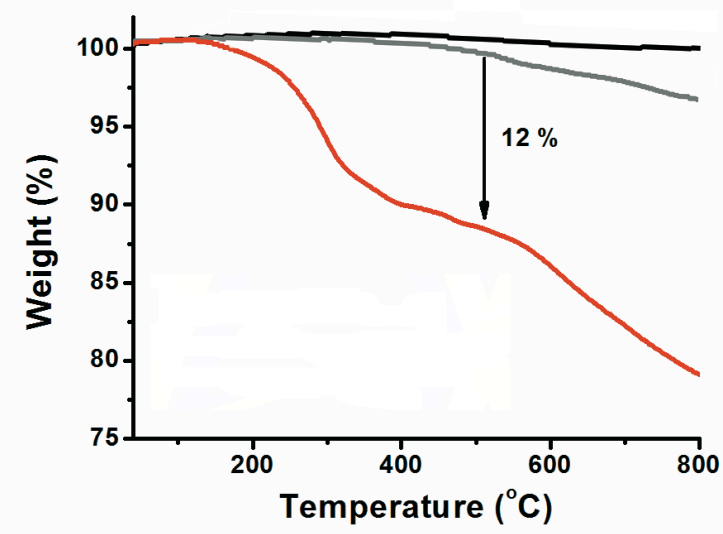

Figure 3. TGA graphs of pristine graphite (black), exfoliated graphene (grey) and ZnPc-graphene 2 (red), obtained under nitrogen.

Steady-state electronic absorption spectroscopy was used to follow the formation of the $\mathrm{ZnPc}$-graphene hybrid material 2. In Figure 4, the absorption spectra of ZnPc 1 and ZnPc-graphene $\mathbf{2}$ in DMF are compared. The absorption spectrum of ZnPc-graphene 2 consists of a broad band centered at $683 \mathrm{~nm}$, followed by smaller absorption bands at 612, and $355 \mathrm{~nm}$ assigned to $\mathrm{ZnPc}$, while graphene contributes to the continuing absorption throughout the UV-Vis and extending into the NIR region. Compared to reference $\mathrm{ZnPc} \mathbf{1}$, the absorption of $\mathrm{ZnPc}$ in hybrid material $\mathbf{2}$ is red-shifted by $2 \mathrm{~nm}$, has lower intensity and appears broadened. These findings based on the optical absorption spectroscopy results not only manifest the efficient formation of $\mathrm{ZnPc}$-graphene, but also give sufficient evidence for ground state electronic interactions between the two species within the hybrid material (even though any aggregation of $\mathrm{ZnPc}$ that may take place would also result in a similar observation), similarly with other studies based on phthalocyanines covalently grafted to carbon nanotubes. ${ }^{58,70,71}$

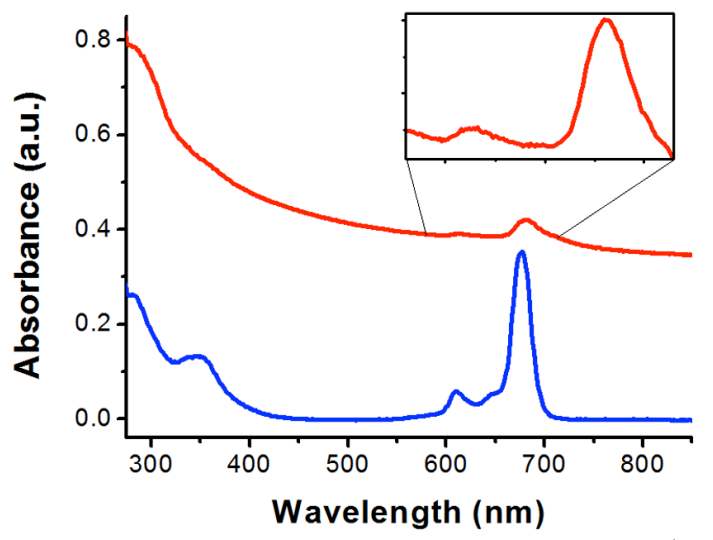

Figure 4. Electronic absorption spectra of $\mathrm{ZnPc} \mathbf{1}$ (blue) and ZnPc-graphene hybrid material 2 (red), obtained in DMF.

Insight of the electronic interplay between $\mathrm{ZnPc}$ and graphene in the excited state is derived from photoluminescence studies. Upon excitation at $350 \mathrm{~nm}$, the strong fluorescence emission of $\mathrm{ZnPc} 1$ at $686 \mathrm{~nm}$ was significantly quenched by the presence of graphene in the ZnPc-graphene hybrid material 2, when measurements performed with matching absorbencies of $\mathrm{ZnPc}$ at the excitation wavelength (Figure 5). The latter observation is indicative of electronic interactions between the singlet excited state of zinc phthalocyanine ${ }^{1}(\mathrm{ZnPc})^{*}$ and graphene, thus suggesting that photoilluminated $\mathrm{ZnPc}$ can transport electrons to the electron accepting graphene sheets, in the ZnPc-graphene hybrid material 2. 


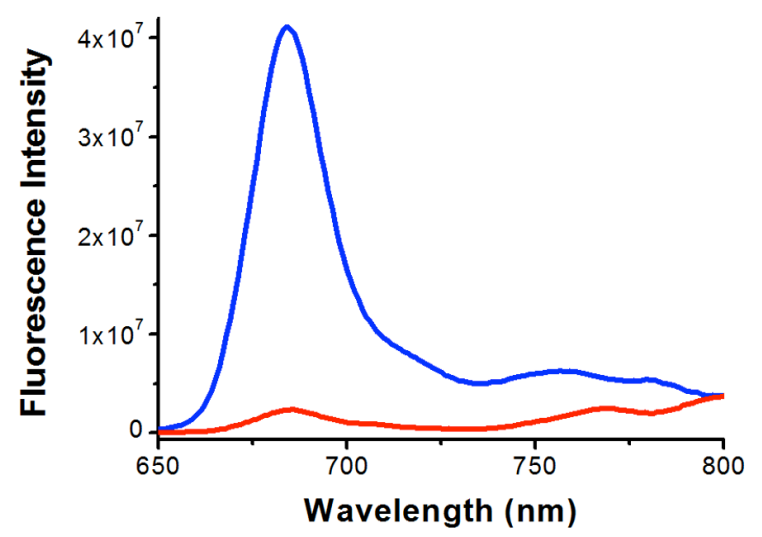

Figure 5. Fluorescence spectra of ZnPc-graphene hybrid material 2 (red) as compared with ZnPc 1 (blue), obtained in DMF. The excitation wavelength was $350 \mathrm{~nm}$ and the concentrations were adjusted so that $\mathrm{ZnPc}$ in the two samples exhibited equal absorbance at the excitation wavelength.

Deeper insight into the excited-state interaction, the $\mathrm{ZnPc}$ emission decays of ZnPc-graphene $\mathbf{2}$ and unbound $\mathrm{ZnPc} 1$ were examined. The charge-transfer interactions between $\mathrm{ZnPc}$ and graphene, as documented from the fluorescence quenching for $\mathrm{ZnPc}$ in hybrid 2, should accelerate the decay of the ZnPc emission. Thus, based on the time-correlated single photon counting (TCSPC) method the fluorescence lifetime profiles for reference $\mathrm{ZnPc} 1$ were obtained (Figure S2 in the SI). The analysis of the time profile of the fluorescence decay at $684 \mathrm{~nm}$ for the singlet excited-state of unbound $\mathrm{ZnPc}$, measured in DMF, was exclusively monoexponentially fitted, with a lifetime of $2.96 \mathrm{~ns}$. However, no fast decaying component of ${ }^{1} \mathrm{ZnPc}^{*}$ in $\mathrm{ZnPc}$-graphene 2 , corresponding to the quenching of the fluorescence intensity in the steadystate spectra, was observed. Implicit is that the singlet excited-state deactivation of $\mathrm{ZnPc}$ in $\mathbf{2}$ is faster than the time resolution of our instrument (i.e. 50 ps). Then, considering the fast decay value of 50 ps as the upper limit of the actual lifetime attributed to ${ }^{1} \mathrm{ZnPc}^{*}$ in $\mathbf{2}$, consistent with the strong emission quenching of $\mathrm{ZnPc}$ by graphene as observed in the corresponding steady-state photoluminescence measurement, the minimum value of the rate constant for charge-separation $\left(k_{\mathrm{CS}}\right)$ can be determined as $1.95 \times 10^{10} \mathrm{~s}^{-1}$. Additionally, the quantum yield for charge separation $\left(\Phi_{\mathrm{CS}}\right)$ is calculated as 0.98 .

Time-resolved transient absorption spectra of ZnPcgraphene $\mathbf{2}$ were measured by femtosecond laser flash photolysis in deaerated $\mathrm{PhCN} .^{72} \mathrm{~A}$ transient absorption spectrum observed at $1 \mathrm{ps}$ after laser pulse excitation $\left(\lambda_{\mathrm{ex}}\right.$ $=393 \mathrm{~nm}$ ) is shown in Figure 6a. The transient absorption band observed at 1 ps clearly showed the singlet excited state of zinc phthalocyanine ${ }^{1} \mathrm{ZnPc}^{*}\left(\lambda_{\max }=590 \mathrm{~nm}\right)^{62,63,73}$, 74 which is overlapped with the strong ground-state bleaching and emission at $680 \mathrm{~nm}$ for the ZnPc moiety and Vis-NIR region for the graphene entity. As electron transfer from ${ }^{1} \mathrm{ZnPc}^{*}$ to graphene proceeds, the transient absorption due to ${ }^{1} \mathrm{ZnPc}^{*}$ disappears, accompanied by the appearance of the transient absorption band due to $\mathrm{ZnPc}^{-+}$. The net change was observed as an increase in bleaching and the red shift of the bleaching peak because of the appearance of the transient absorption at $530 \mathrm{~nm}$ due to $\mathrm{ZnPc}^{\circ}{ }^{60}$ Additionally, it has been reported that $\mathrm{ZnPc}^{\cdot+}$ also shows an absorption band at $840 \mathrm{~nm} \cdot{ }^{75,76}$ This band is known to be broadened by strong $\pi-\pi$ interactions. ${ }^{65}$ Therefore, no observation of the absorption band at $840 \mathrm{~nm}$ in Figure 6a together the red shift and broadening of the absorption band in Figure 4 suggests strong $\pi-\pi$ interactions of $\mathrm{ZnPc}^{*+}$ with graphene. Although this interpretation has yet to be clearly proven, the time profile of transient absorption at $620 \mathrm{~nm}$ clearly consists of two steps (Figures $6 \mathrm{~b}$ and $6 \mathrm{c}$ ) ${ }^{77}$ which may well be assigned to the charge separation to form the chargeseparated state $\left(\mathrm{ZnPc}^{-+}\right.$-graphene $\left.{ }^{--}\right)$and the charge recombination, judging from the observation of the chargeseparated state by EPR measurements (vide infra).
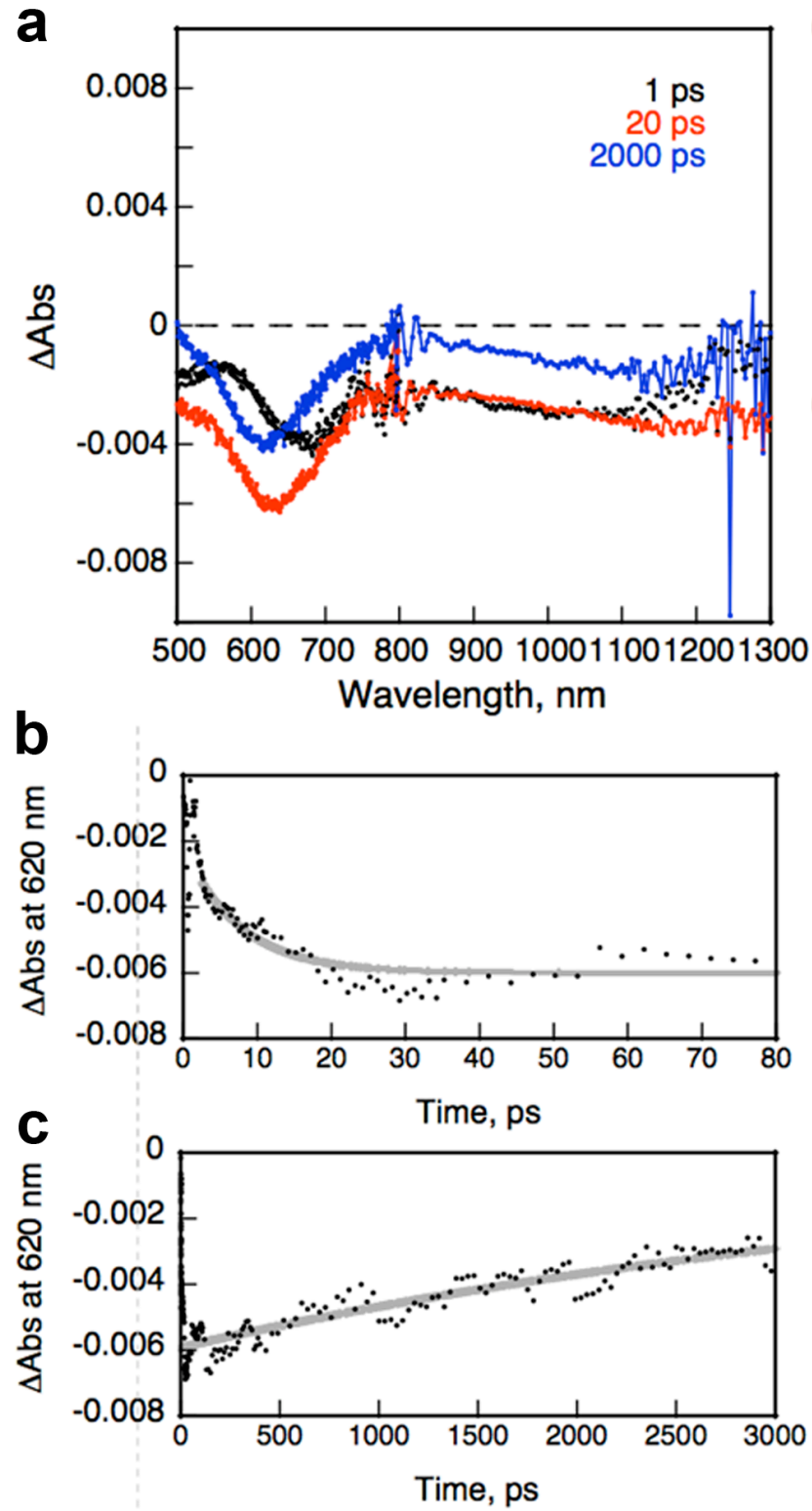

Figure 6. a) Transient absorption spectra of ZnPcgraphene hybrid material 2 in PhCN observed at 1, 20, 2000 ps after femtosecond laser excitation $(\lambda=393 \mathrm{~nm})$. b) Time profiles of absorbance at $620 \mathrm{~nm}$ (b) fast and (c) slow time ranges. 
The rate constant of photoinduced electron transfer was determined from mono-exponential analysis of the photo bleaching time profile at $620 \mathrm{~nm}$ (Figure 6b) to be $1.3 \times 10^{11} \mathrm{~s}^{-1}$ (lifetime $\left.=7.7 \mathrm{ps}\right) .^{78}$ The transient absorption bands of charge-separated state with bleaching was recovered slowly with the rate constant of $2.3( \pm 0.5) \times 10^{8} \mathrm{~s}^{-1}$ (Figure 6c). The lifetime of charge-separated state was determined as $4.3( \pm 0.8) \mathrm{ns}$.

To detect the charge-separated state, we measured EPR spectrum of a PhCN glass containing ZnPc-graphene hybrid material 2 under photoirradiation by a high-pressure Hg lamp $(\lambda>340 \mathrm{~nm})$ at $77 \mathrm{~K}$. The infrared region was cut off by using a water filter to avoid thermal decomposition of 2. A single EPR spectrum was observed at $g=$ 2.0028 (Figure 7). This $g$ value agrees well with that of $\mathrm{ZnPc}^{+}$(2.003), ${ }^{79},{ }^{80}$ which is clearly different from that observed in mechanically exfoliated graphene (2.0045). ${ }^{81}$ No signal of graphene radical anion was observed under the present experimental conditions because the graphene radical anion may have a very broad signal to be detected or disproportionate between two graphene radical anions on the same sheet to generate diamagnetic species. $^{82-85}$

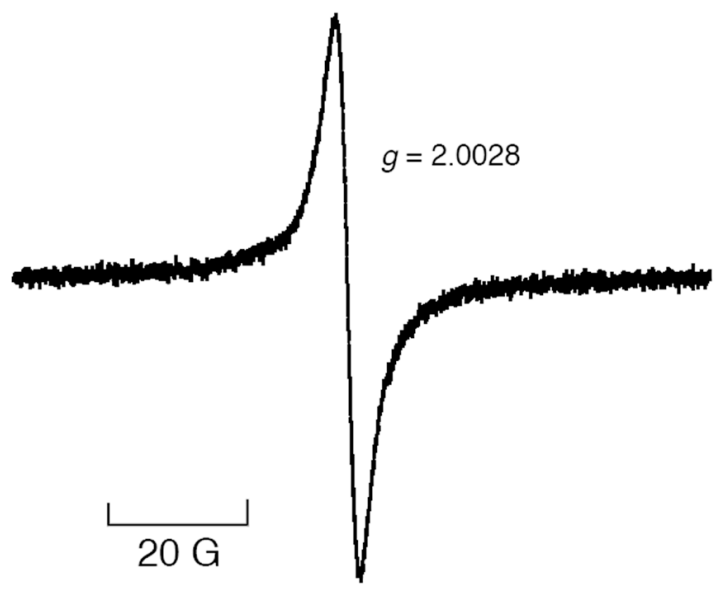

Figure 7. EPR spectrum observed under photoirradiation of a deaerated $\mathrm{PhCN}$ glass of $\mathrm{ZnPc}$-graphene hybrid material 2 at $77 \mathrm{~K}$.

The photoelectrochemical properties of ZnPc-graphene 2 were evaluated by fabricating thin films of $\mathrm{ZnPc}-$ graphene 2 onto nanostructured $\mathrm{SnO}_{2}$ onto an optical transparent electrode (OTE) by electrophoretic deposition. A suspension of ZnPc-graphene 2 in THF $(\sim 2 \mathrm{~mL})$ was transferred into a cuvette, in which the two electrodes OTE and OTE $/ \mathrm{SnO}_{2}$ were placed and kept at $5 \mathrm{~cm}$ distance by a Teflon spacer. Then, application of dc electric field $(\sim 100 \mathrm{~V} / \mathrm{cm})$ resulted in the deposition of $\mathrm{ZnPc}-$ graphene $\mathbf{2}$ from the suspension to the electrode surface and the formation of a robust thin film of $\mathrm{OTE} / \mathrm{SnO}_{2} / \mathrm{ZnPc}$-graphene, as documented by discoloration of the suspension and the simultaneous coloration of the OTE $/ \mathrm{SnO}_{2}$ electrode. For reference purposes, a thin film of only graphene, in the absence of $\mathrm{ZnPc}$, was analogously deposited onto the electrode surface to form $\mathrm{OTE} / \mathrm{SnO}_{2} /$ graphene. Steady-state electron absorption spectroscopy was used to follow the deposition of the ZnPc-graphene hybrid material onto the electrode surface. In the UV-Vis absorption spectrum of the $\mathrm{OTE} / \mathrm{SnO}_{2} / \mathrm{ZnPc}$-graphene electrode (Figure $\mathrm{S}_{3}$ in the SI) the characteristic ZnPc band is identified at around 610 $\mathrm{nm}$. However, it is found further broadened, as compared with the corresponding band in ZnPc-graphene $\mathbf{2}$ in solution (cf. Figure 4), most likely due to aggregation of $\mathrm{ZnPc}$ moieties and/or electronic interactions between $\mathrm{ZnPc}$ and graphene. On the other hand, the $\mathrm{OTE} / \mathrm{SnO}_{2} /$ graphene electrode shows continuous featureless absorbance in the visible region due to graphene, mirroring the observation registered in solution.

Photoelectrochemical measurements were performed in a standard two-compartment cell, in acetonitrile containing $0.5 \mathrm{M} \mathrm{LiI}$ and $0.01 \mathrm{M} \mathrm{I}_{2}$ as redox electrolyte and $\mathrm{OTE} / \mathrm{SnO}_{2} / \mathrm{ZnPc}$-graphene as working electrode, while $\mathrm{Pt}$ wire was the counter electrode. ${ }^{86-90}$ The photocurrent response of $\mathrm{OTE} / \mathrm{SnO}_{2} / \mathrm{ZnPc}$-graphene electrode obtained under white light illumination (AM 1.5 condition; input power $\left.100 \mathrm{~mW} \cdot \mathrm{cm}^{-2}\right)$ is presented in Figure 8. Evidently, the response found to be prompt, steady and reproducible during repeated on/off cycles of the visible light illumination. A short circuit photocurrent density $\left(I_{s c}\right)$ of $20 \mu \mathrm{A} \cdot \mathrm{cm}^{-2}$ was measured following the excitation of OTE $/ \mathrm{SnO}_{2} / \mathrm{ZnPc}$-graphene electrode, while blank experiments conducted with $\mathrm{OTE} / \mathrm{SnO}_{2}$ produced no detectable photocurrent under similar experimental conditions.

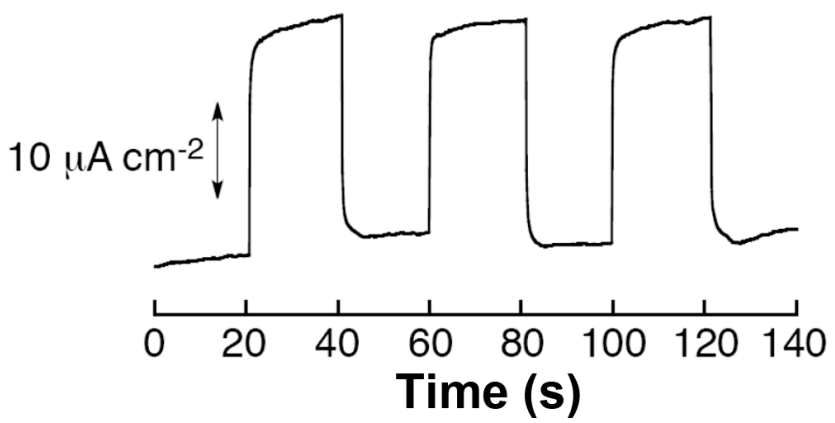

Figure 8. Photocurrent responses of OTE/ $/ \mathrm{SnO}_{2} / \mathrm{ZnPc}-$ graphene under white light illumination (AM 1.5 condition). Input power: $100 \mathrm{~mW} \cdot \mathrm{cm}^{-2}$.

Moreover, the photocurrent action spectrum of $\mathrm{OTE} / \mathrm{SnO}_{2} / \mathrm{ZnPc}$-graphene electrode was evaluated and compared with that of OTE/SnO $\mathrm{S}_{2} /$ graphene (Figure 9), by examining the wavelength dependence of the incident photon-to-current conversion efficiency (IPCE). The IPCE values were calculated by normalizing the photocurrent densities for incident light energy intensity using the following equation: ${ }^{91-93}$

$$
\operatorname{IPCE}(\%)=100 \times 1240 \times I_{\mathrm{sc}} /\left(W_{\text {in }} \times \lambda\right),
$$

where $I_{\mathrm{sc}}$ is the short circuit photocurrent $\left(\mathrm{A} \cdot \mathrm{cm}^{-2}\right), W_{\text {in }}$ is the incident light intensity $\left(\mathrm{W} \cdot \mathrm{cm}^{-2}\right)$, and $\lambda$ is the wavelength in $\mathrm{nm}$. Thus, the photocurrent action spectrum of $\mathrm{OTE} / \mathrm{SnO}_{2} / \mathrm{ZnPc}$-graphene electrode, recorded by using a standard two-compartment cell equipped with a potentiostat, shows a IPCE value of $\mathbf{2 . 2} \%$ at $420 \mathrm{~nm}$ which is 
almost one order of magnitude higher than the corresponding value for $\mathrm{OTE} / \mathrm{SnO}_{2} /$ graphene electrode, under the same experimental conditions (Figure 9). ${ }^{93}$

In this context, the anodic photocurrent observed for $\mathrm{OTE} / \mathrm{SnO}_{2} / \mathrm{ZnPc}$-graphene films indicates electron transfer from the photoexcited $\mathrm{ZnPc}$ to graphene and highlights the significance of excited-state interactions between $\mathrm{ZnPc}$ and graphene in hybrid material 2 for generating a photoelectrochemical effect.

In brief, the process responsible for the photocurrent generation includes electron-transfer from the photoexcited $\mathrm{ZnPc}$ to exfoliated graphene, followed by electron mediation from the reduced graphene layers to the conduction band of $\mathrm{SnO}_{2}$ electrode. Importantly, it is worth mentioning that an IPCE value of only $0.3 \%$ was registered for non-covalently interacting $\mathrm{ZnPc}$ with graphene, ${ }^{32}$ thus, highlighting the significant role of having the $\mathrm{ZnPc}$ anchored through a stable and robust bond onto the graphene sheet, for enhancing photoinduced intrahybrid electron transfer phenomena between the two components and achieving higher IPCE values.

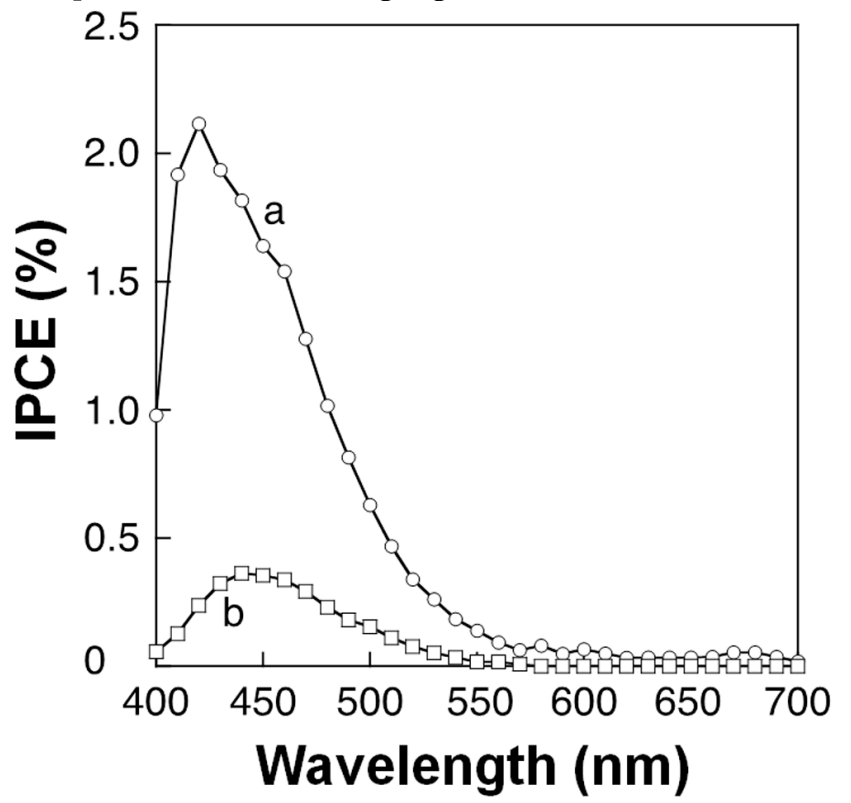

Figure 9. Photocurrent action spectra of (a) $\mathrm{OTE} / \mathrm{SnO}_{2} / \mathrm{ZnPc}$-graphene and (b) OTE/SnO$/$ graphene (two-electrode system). Electrolyte: $0.5 \mathrm{M} \mathrm{LiI}$ and $0.01 \mathrm{M} \mathrm{I}_{2}$ in acetonitrile.

\section{CONCLUSION}

Graphene sheets were exfoliated with the aid of sonication in $o$-DCB. Then, zinc phthalocyanine $(\mathrm{ZnPc})$ was covalently anchored onto exfoliated graphene, forming electron donor-acceptor ZnPc-graphene hybrid material 2. The new hybrid material 2 was thoroughly characterized with spectroscopic, thermal and microscopy techniques. Based on absorption studies, ground state intrahybrid electronic interactions found to exist, leading to red-shift and broadening of the characteristic absorption bands of ZnPc in hybrid material 2, as compared with the corresponding absorption features of reference ZnPc 1. In addition, steady-state fluorescence emission measure- ments revealed efficient quenching of the characteristic $\mathrm{ZnPc}$ emission in hybrid material 2, suggesting the presence of electronic interactions in the excited states. The dynamics of the system were studied by complementary means, including time-resolved fluorescence spectroscopy, femtosecond transient absorption spectroscopy and EPR, thus, revealing charge-separation generating $\mathrm{ZnPc}^{\circ+}$ graphene $^{--}$via the singlet excited state of ZnPc. Finally, a photoelectrochemical cell based on the fabrication of ZnPc-graphene as a photoanode onto an optical transparent electrode (OTE) cast with nanostructured $\mathrm{SnO}_{2}$ films $\left(\mathrm{OTE} / \mathrm{SnO}_{2}\right)$ was constructed. The film of the $\mathrm{OTE} / \mathrm{SnO}_{2} / \mathrm{ZnPc}$-graphene electrode revealed prompt, stable and reproducible photocurrent, while the IPCE value was measured. Overall, this is a promising and leading initiative for hybrid materials combining graphene and photoactive moieties for applications in solar cells.

Note added in proof. During the submission of the current work, we noticed that a similar hybrid material in which metal-free phthalocyanine condensed through a long bridge onto pyrrolidine functionalized graphene was just synthesized and shown the formation of charge-separated states upon photoirradiation. ${ }^{94}$

\section{ASSOCIATED CONTENT}

Supporting Information. ATR-IR of $\mathrm{ZnPc}$ and $\mathrm{ZnPc}-$ graphene, fluorescence decay profile of $\mathrm{ZnPc}$, absorption spectra of OTE/SnO$/ 2 / \mathrm{ZnPc}$-graphene film. This material is available free of charge via the Internet at http://pubs.acs.org.

\section{AUTHOR INFORMATION}

\section{Corresponding Author}

tagmatar@eie.gr; asastre@umh.es; hasobe@chem.keio.ac.jp; fukuzumi@chem.eng.osaka-u.ac.jp

\section{Author Contributions}

The manuscript was written through contributions of all authors. All authors have given approval to the final version of the manuscript.

\section{ACKNOWLEDGMENT}

Partial financial support from GSRT/NSRF 2007-2013 the actions "Cooperation" through Project o9 $\sum \mathrm{YN}-42-691$ and "Postdoctoral support" Project GRAPHCELL PE5(2126) as well as COST network MPogor NanoTP to N.T. is acknowledged. This work was also partially supported by Grant-inAids for Scientific Research (No. 23108721 \& 23681025 to T.H., No. 20108010 to S.F., No. 23750014 to K.O.), the Science Research Promotion Fund from the Promotion and Mutual Aid Corporation for Private Schools from the Ministry of Education, Culture, Sports, Science and Technology, Japan, and a WCU project (R31-2008-ooo-10o10-o) through KOSEF/MEST, Korea. Grants Consolider-Ingenio 2010 project HOPE CSD2007-00007, and CTQ2011-26455 from MINECO and FEDER to A. S.-S. are acknowledged.

\section{REFERENCES}


(1) Novoselov, K. S.; Geim, A. K.; Morozov, S. V.; Jiang, D.; Zhang, Y.; Dubonos, S. V.; Grigorieva, I. V.; Firsov, A. A. Science 2004, 306, 666-669.

(2) Geim, A. K.; Novoselov, K. S. Nat. Mater. 2007, 6, 183-191.

(3) Nair, R. R.; Blake, P.; Grigorenko, A. N.; Novoselov, K. S.; Booth, T. J.; Stauber, T.; Peres, N. M. R.; Geim, A. K. Science 2008, 320, 1308-1308.

(4) Lee, C.; Wei, X.; Kysar, J. W.; Hone, J. Science 2oo8, 321, 385-388.

(5) Novoselov, K. S.; Jiang, D.; Schedin, F.; Booth, T. J.; Khotkevich, V. V.; Morozov, S. V.; Geim, A. K. Proc. Natl. Acad. Sci. U. S. A. 2005, 102, 10451-10453.

(6) Novoselov, K. S.; Geim, A. K.; Morozov, S. V.; Jiang, D.; Katsnelson, M. I.; Grigorieva, I. V.; Dubonos, S. V.; Firsov, A. A. Nature 2005,438, 197-200.

(7) Morozov, S. V.; Novoselov, K. S.; Katsnelson, M. I.; Schedin, F.; Elias, D. C.; Jaszczak, J. A.; Geim, A. K. Phys. Rev. Lett. 2008, 100, 016602-016605.

(8) Bai, H.; Li, C.; Shi, G. Adv. Mater. 2011, 23, 1089-1115.

(9) Kamat, P. V. J. Phys. Chem. Lett. 2011, 2, 242-251.

(10) Loh, K. P.; Bao, Q.; Ang, P. K.; Yang, J. J. Mater. Chem. 2010, 20, 2277-2289.

(11) Dreyer, D. R.; Park, S.; Bielawski, C. W.; Ruoff, R. S. Chem. Soc. Rev. 2010, 39, 228-240.

(12) Hernandez, Y.; Nicolosi, V.; Lotya, M.; Blighe, F. M.; Sun, Z.; De, S.; McGovern, I. T.; Holland, B.; Byrne, M.; Gun'Ko, Y. K. et al. J. N. Nat. Nanotechnol. 2oo8, 3, 563568.

(13) Hamilton, C. E.; Lomeda, J. R.; Sun, Z.; Tour, J. M.; Barron, A. R. Nano Lett. 2009, 9, 3460-3462.

(14) Coleman, J. N. Adv. Funct. Mater. 2009, 19, 3680-3695.

(15) Behabtu, N.; Lomeda, J. R.; Green, M. J.; Higginbotham, A. L.; Sinitskii, A.; Kosynkin, D. V.; Tsentalovich, D.; Parra-Vasquez, A. N. G.; Schmidt, J.; Kesselman, E. et al. Nat. Nanotechnol. 2010, 5, 406-411.

(16) Lotya, M.; King, P. J.; Khan, U.; De, S.; Coleman, J. N. ACS Nano 2010, 4, 3155-3162.

(17) Yan, X.; Li, L.-s. J. Mater. Chem. 2011, 21, 3295-330o.

(18) Gupta, B. K.; Thanikaivelan, P.; Narayanan, T. N.; Song, L.; Gao, W.; Hayashi, T.; Leela Mohana Reddy, A.; Saha, A.; Shanker, V.; Endo, M. et al. Nano Lett. 2011, 11, 52275233.

(19) Goncalves, G.; Marques, P. A. A. P.; Granadeiro, C. M.; Nogueira, H. I. S.; Singh, M. K.; Grácio, J. Chem. Mater. 2009, 21, 4796-4804

(20) Cao, A.; Liu, Z.; Chu, S.; Wu, M.; Ye, Z.; Cai, Z.; Chang, Y.; Wang, S.; Gong, Q.; Liu, Y. Adv. Mater. 2010, 22, 103-106.

(21) Xu, Y.; Liu, Z.; Zhang, X.; Wang, Y.; Tian, J.; Huang, Y.; Ma, Y.; Zhang, X.; Chen, Y. Adv. Mater. 2009, 21, 12751279.

(22) Karousis, N.; Economopoulos, S. P.; Sarantopoulou, E.; Tagmatarchis, N. Carbon 2010, 48, 854-86o.

(23) Tu, W.; Lei, J.; Zhang, S.; Ju, H. Chem.-Eur. J. 2o1o, 16, 10771-10777.

(24) Karousis, N.; Sandanayaka, A. S. D.; Hasobe, T.; Economopoulos, S. P.; Sarantopoulou, E.; Tagmatarchis, N. J. Mater. Chem. 2011, 21, 109-117.

(25) Wang, H.-X.; Zhou, K.-G.; Xie, Y.-L.; Zeng, J.; Chai, N.-N.; Li, J.; Zhang, H.-L. Chem. Commun. 2o11, 47, 5747-5749.

(26) Zhang, X.; Hou, L.; Cnossen, A.; Coleman, A. C.; Ivashenko, O.; Rudolf, P.; van Wees, B. J.; Browne, W. R.; Feringa, B. L. Chem.-Eur. J. 2011, 17, 8957-8964.

(27) An, X.; Simmons, T.; Shah, R.; Wolfe, C.; Lewis, K. M.; Washington, M.; Nayak, S. K.; Talapatra, S.; Kar, S. Nano Lett. 2010, 10, 4295-4301.

(28) An, X.; Butler, T. W.; Washington, M.; Nayak, S. K.; Kar, S. ACS Nano 2011, 5, 1003-1011.
(29) Mann, J. A.; Rodríguez-López, J.; Abruña, H. D.; Dichtel, W. R. J. Am. Chem. Soc. 2o11, 133, 17614-17617.

(30) Das, B.; Voggu, R.; Rout, C. S.; Rao, C. N. R. Chem. Commun. 2008, 5155-5157.

(31) Economopoulos, S. P.; Rotas, G.; Miyata, Y.; Shinohara, H.; Tagmatarchis, N. ACS Nano 2010, 4, 7499-7507.

(32) Malig J.; Jux N.; Kiessling, D.; Cid, J.-J.; Vázquez, P.; Torres, T.; Guldi D. M. Angew. Chem., Int. Ed. 2011, 50, 3561.

(33) de la Torre, G.; Claessens, C. G.; Torres T. Chem. Commun. 2007, 2000-2002.

(34) Phthalocyanines: Properties and Applications; Leznoff, C. C.; Lever, A. B. P., Eds., VCH Publishers: New York, 1990 - 1996; Vol. 1-4.

(35) Ben-Hur, E., Chan, W.-S. (2003) Phthalocyanines in photobiology and their medical applications. In The Porphyrin Handbook (Kadish, K. M., Smith, K. M., Guilard, R., Eds.) Vol. 19, pp 1-35, Academic Press, Boston.

(36) Ali, H.; van Lier, J. E. Chem. Rev. 1999, 99, 2379-2450.

(37) Ince, M.; Martínez-Díaz, M. V.; Barberá, J.; Torres, T. J. Mater. Chem. 2011, 21, 1531-1536.

(38) Hayashi, H.; Nihashi, W.; Umeyama, T.; Matano, Y.; Seki, S.; Shimizu, Y.; Imahori, H. J. Am. Chem. Soc. 2011, 133, 10736-10739.

(39) de la Torre, G.; Vázquez, P.; Agulló-López, F.; Torres, T. Chem. Rev. 2004, 104, 3723-3750.

(40) Chen, Y.; Hanack, M.; Blau, W. J.; Dini, D.; Liu, Y.; Lin, Y.; Bai, J. J. Mat. Sci. 2006, 41, 2169-2185.

(41) Fischer, M. K. R; López-Duarte, I.; Wienk, M. M.; Martínez-Díaz, M. V.; Janssen, R. A. J.; Bauerle, P.; Torres, T., J. Am. Chem. Soc. 2oo9, 131, 8669-8676.

(42) Varotto, A.; Nam, C.-Y.; Radivojevioc, I.; Tomé, J.P.C.; Cavaleiro, J.A.S.; Black, C.T.; Drain, C.M. J. Am. Chem. Soc. 2010, 132, 2552-2554.

(43) Lee, J. U.; Kim, Y. D.; Jo, J. W.; Kim J. P.; Jo W. H. J. Mater. Chem. 2011, 21, 17209-17218.

(44) Grätzel, M. Acc. Chem. Res. 2009, 42, 1788-1798.

(45) Barea, E. M.; Ortiz, J.; Paya, F. J.; Fernández-Lázaro, F.; Fabregat-Santiago, F.; Sastre-Santos A.; Bisquert, J. Energy Environ. Sci. 2010, 3, 1985-1994.

(46) Martínez-Díaz, M. V.; Ince, M.; Torres, T. Monatsh. Chem. 2011, 142, 699-707.

(47) Cid, J. J.; Yum, J. H.; Jang S. R.; Nazeeruddin, M. K.; Martínez-Ferrero, E.; Palomares, E.; Ko, J.; Grätzel, M.; Torres, T. Angew. Chem., Int. Ed. 2007, 46, 8358-8362.

(48) Mori, S.; Nagata, M.; Nakahata, Y.; Yasuta, K.; Goto, R.; Kimura, M.; Taya, M. J. Am. Chem. Soc 2010, 132, 40544055.

(49) Ragoussi, M.-E.; Cid, J.-J.; Yum, J.-H.; de la Torre, G., di Censo, D.; Grätzel, M.; Nazeeruddin, M. K., Torres, T. Angew. Chem., Int. Ed. 2012, 51, 4375-4378.

(50) García-Iglesias, M.; Yum, J. H.; Humphry-Baker, R.; Zakeeruddin, S. M.; Pechy, P.; Vázquez, P.; Palomares, E.; Grätzel, M.; Nazeeruddin, M. K.; Torres, T. Chem. Sci., 2011, 2, 1145-1150.

(51) Elemans, J. A. A. W.; van Hameren, R.; Nolte, R. J. M.; Rowan, A. E. Adv. Mater. 20o6, 18, 1251-1266.

(52) Bottari, G.; de la Torre, G.; Guldi, D. M.; Torres T. Chem. Rev. 2010, 110, 6768-6816.

(53) Sastre, A.; Gouloumis, A.; Vazquez, P.; Torres, T.; Doan, V.; Schwartz, B. J.; Wudl, F.; Echegoyen, L.; Rivera, J. Org. Lett. 1999, 1, 1807-1810.

(54) Gouloumis, A.; Liu, S. G.; Sastre, A.; Vazquez, P.; Echegoyen, L.; Torres, T. Chem. Eur. J. 2ooo, 6, 3600-3607.

(55) Martin-Gomis, L.; Ohkubo, K.; Fernandez-Lazaro, F.; Fukuzumi, S.; Sastre-Santos, A. Org. Lett. 2007, 9, 34413444 . 
(56) Pinzón, J. R.; Cardona, C. M.; Herranz, M. A.; PlonskaBrzezinska, M. E.; Palkar, A.; Athans, A. J.; Martín, N.; Rodríguez-Fortea, A.; Poblet, J. M.; Bottari, G. et al. Chem.-Eur. J. 2009, 15, 864-877.

(57) Rotas, G.; Ranta, J.; Efimov, A.; Niemi, M.; Lemmetyinen, H.; Tkachenko, N.; Tagmatarchis, N. ChemPhysChem 2012, 13, 1246-1254.

(58) Campidelli, S.; Ballesteros, B.; Filoramo, A.; Díaz Díaz, D.; de la Torre, G.; Torres, T.; Rahman, G. M. A.; Ehli, C.; Kiessling, D.; Werner, F. et al. J. Am. Chem. Soc. 2oo8, 130, 11503-11509.

(59) Li, X.; Sinks, L. E.; Rybtchinski, B.; Wasielewski, M. R. J. Am. Chem. Soc. 2004, 126, 10810-10811.

(6o) Fukuzumi, S.; Ohkubo, K.; Ortiz, J.; Gutiérrez, A. M.; Fernández-Lázaro, F.; Sastre-Santos, A. Chem. Commun. 2005, 3814-3816.

(61) Rodríguez-Morgade, M. S.; Torres, T.; AtienzaCastellanos, C.; Guldi, D. M. J. Am. Chem. Soc. 20o6, 128, 15145-15154.

(62) Fukuzumi, S.; Ohkubo, K.; Ortiz, J.; Gutiérrez, A. M.; Fernández-Lázaro, F.; Sastre-Santos, A. J. Phys. Chem. A 2008, 112, 10744-10752.

(63) Céspedes-Guirao, F. J.; Ohkubo, K.; Fukuzumi, S.; SastreSantos, Á.; Fernández-Lázaro, F. J. Org. Chem. 2009, 74, 5871-5880.

(64) Albert-Seifried, S.; Finlayson, Chris E.; Laquai, F.; Friend, R. H.; Swager, T. M.; Kouwer, P.H. J.; Juríček, M.; Kitto, H. J.; Valster, S.; Nolte, R. J. M. et al. Chem.-Eur. J. 2010, 16, 10021-10029.

(65) Céspedes-Guirao, F. J.; Martín-Gomis, L.; Ohkubo, K.; Fukuzumi, S.; Fernández-Lázaro, F; Sastre-Santos, Á. Chem.-Eur. J. 2011, 17, 9153-9163.

(66) Céspedes-Guirao, F. J.; Ohkubo, K.; Fukuzumi, S.; Fernández-Lázaro, F.; Sastre-Santos, Á. Chem.-Asian J. 2011, 11, 3110-3121.

(67) Basiuk, E. V.; Monroy-Peláez, M.; Puente-Lee, I.; Basiuk, V. A. Nano Lett. 2004, 4, 863-866.

(68) Cioffi, C.; Campidelli, S.; Sooambar, C.; Marcaccio, M.; Marcolongo, G.; Meneghetti, M.; Paolucci, D.; Paolucci, F.; Ehli, C.; Rahman, G. M. A. et al. J. Am. Chem. Soc. 2007, 129, 3938-3945.

(69) Sibrian-Vazquez, M.; Ortiz, J; Nesterova, I. V.; Fernández-Lázaro F.; Sastre-Santos, Á.; Soper, S. A.; Vicente M. G. H. Bioconjugate Chem. 2007, 18, 410-420.

(70) Mugadza, T.; Nyokong, T. Synth. Met. 2010, 16o, 20892098.

(71) Chidawanyika, W.; Nyokong, T. Carbon 2o1o, 48, 28312338.

(72) The femtosecond laser flash photolysis measurements were also carried out in DMF $\left(\varepsilon_{\mathrm{s}}=36.7\right)$, which is more polar than $\mathrm{PhCN}\left(\varepsilon_{\mathrm{s}}=25.2\right)$. However, we could not detect the charge-separated state probably because of the much faster decay of the charge-separated state in DMF than in PhCN. The driving force of charge recombination in DMF will be smaller than that in PhCN which may result in acceleration of the charge recombination in the Marcus inverted region; see: Imahori, H.; Tamaki, K.; Guldi, D. M.; Luo, C.; Fujitsuka, M.; Ito, O.; Sakata, Y.; Fukuzumi, S. J. Am. Chem. Soc. 2001, 123, 2607-2617.

(73) Jiménez, A. J.; Spänig, F.; Rodríguez-Morgade, M. S.; Ohkubo, K.; Fukuzumi, S.; Guldi D. M.; Torres, T. Org. Lett. 2007, 9, 2481-2484.

(74) Blas-Ferrando, V. M.; Ortiz, J.; Bouissane, L.; Ohkubo, K.; Fukuzumi, S.; Fernández-Lázaro, F.; Sastre-Santos, Â. Chem. Commun. 2012, 48, 6241-6243.

(75) Guldi, D. M.; Zilbermann, I.; Gouloumis, A.; Vázquez, P.; Torres, T. J. Phys. Chem. B 2004, 108, 18485-18494.
(76) Supur, M.; Yamada, Y.; El-Khouly, M. E.; Honda, T.; Fukuzumi, S. J. Phys. Chem. C 2011, 115, 15040-15047.

(77) The time profile of transient absorption at $620 \mathrm{~nm}$ was recorded to determine the rate constants because the absorption change is maximum at $620 \mathrm{~nm}$.

(78) The lifetime of $\mathbf{2}$ is much shorter than the fluorescence lifetime ( $150 \mathrm{ps})$ expected from the strong fluoresence quenching $(\sim 5 \%)$ and the fluorescence lifetime of $\mathbf{1}$ ( $\sim$ nns). However, the quantitative discussion on the quenching efficiency is difficult because the small portion of $\mathrm{ZnPc}$ which is not attached to graphene results in fluorescence.

(79) Fu, Y.; Fu, G.; Lever, A. B. P. Inorg. Chem. 1994, 33, 10381044 .

(8o) Niemi, M.; Tkachenko, N. V.; Efimov, A.; Lehtivouori, H.; Ohkubo, K.; Fukuzumi, S.; Lemmetyinen, H. J. Phys. Chem. A 2008, 112, 6884-6892.

(81) Ciric, L.; Sienkiewicz, A.; Náfrádi, B.; Mionic, M.; Magrez, A.; Forró, L. Phys. Status Solidi B 2009, 246, 2558-2561.

(82) Saito, K.; Ohtani, M.; Fukuzumi, S. J. Am. Chem. Soc. 2006, 128, 14216-14217.

(83) Saito, K.; Ohtani, M. Fukuzumi, S. Chem. Commun. 2007, $55-57$.

(84) Ohtani, M.; Saito, K. Fukuzumi, S. Chem.-Eur. J. 2oo9, 15, 916o-9168.

(85) Kojima, T.; Nakanishi, T.; Harada, R.; Ohkubo, K.; Yamauchi, S.; Fukuzumi, S. Chem.-Eur. J. 2007, 13, 87148725 .

(86) Pagona, G.; Sandanayaka, A. S. D.; Hasobe, T.; Charalambidis, G.; Coutsolelos, A. G.; Yudasaka, M.; Iijima, S.; Tagmatarchis, N. J. Phys. Chem. C 20o8, 112, 15735-15741.

(87) Vizuete, M.; Gomez-Escalonilla, M. J.; Fierro, J. L. G.; Sandanayaka, A. S. D.; Hasobe, T.; Yudasaka, M.; Iijima, S.; Ito, O.; Langa, F. Chem.-Eur. J. 2010, 16, 10752-10763.

(88) Kongkanand, A.; Tvrdy, K.; Takechi, K.; Kuno, M.; Kamat, P. V. J. Am. Chem. Soc. 2008, 130, 4007-4015.

(89) Kamat, P. V. J. Phys. Chem. C 20o8, 112, 18737-18753.

(9o) Lee, H. J.; Yum, J. H.; Leventis, H. C.; Zakeeruddin, S. M.; Haque, S. A.; Chen, P.; Seok, S. I.; Grätzel, M.; Nazeeruddin, M. K. J. Phys. Chem. C 2oo8, 112, 11600-11608.

(91) Hasobe, T.; Kashiwagi, Y.; Absalom, M. A.; Sly, J.; Hosomizu, K.; Crossley, M. J.; Imahori, H.; Kamat, P. V.; Fukuzumi, S. Adv. Mater. 2004, 16, 975-979.

(92) Hasobe, T.; Kamat, P. V.; Absalom, M. A.; Kashiwagi, Y.; Sly, J.; Crossley, M. J.; Hosomizu, K.; Imahori, H.; Fukuzumi, S. J. Phys. Chem. B 2004, 108, 12865-12872.

(93) The main reason for the difference between IPCE (Fig. 9) and absorption (Fig. S3) spectra is due to the measurement setup in the electrolyte system $\left(\mathrm{SnO}_{2}\right.$ nanocrystallites and $\mathrm{I}^{-} / \mathrm{I}_{3}{ }^{-}$redox couple in acetonitrile) since the incident light is absorbed by the electrolyte solution and $\mathrm{SnO}_{2}$ nanocrystallites in the short wavelength region. In the long wavelength region, the large scattering or aggregate trend may have an effect on the low IPCE value. See the following related papers: Hasobe, T.; Fukuzumi, S.; Kamat, P. V. J. Phys. Chem. B, 2006, 110, 2547725484; Hasobe, T.; Fukuzumi, S.; Kamat, P. V. Angew. Chem. Int. Ed. 2006, 45, 755-759.

(94) Ragoussi, M.-E.; Malig, J.; Katsukis, G.; Butz, B.; Spiecker, E.; de la Torre, G.; Torres, T.; Guldi, D. M. Angew. Chem., Int. Ed. 2012, 51, 6421-6425. 
Table of Contents (TOC)

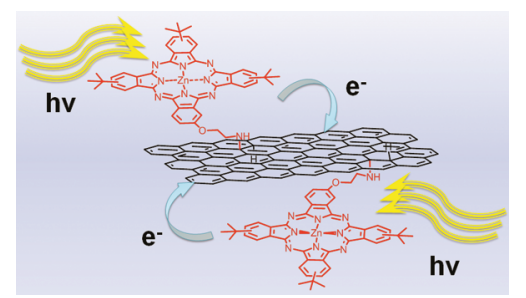

